\title{
Protein Structure of Wheat and Factors Effect on Wheat Protein Quality
}

\author{
Elif Özdemir ${ }^{1}$ and Süleyman Soylu ${ }^{1}$ \\ ${ }^{1}$ Selcuk University; Agriculture Faculty, Crop Science Department, Konya/TURKEY
}

\begin{abstract}
Wheat is one of the three most important crops in the world with maize and rice. Wheat can be cultivated at a wide range of areas of the world like Argentina, Scandinavia and some tropic areas. Although a lot of factors that can provide benefits to wheat quality, factors trigger wheat dough formation and conversion of wheat to other products are much more important. Nowadays grain quality means grain protein composition that is effected too much from genotype and environment. Genetic effects are take source from qualitative variations like protein polymorphism and quantitative variations like total protein or different protein units and subunits. Environmental factors show their effects as quantitative variations like total protein or protein unit and subunits. Protein composition is the most important parameter of determining last process of wheat grain. In spite of determination grain qualitative composition genetically, quantitative composition is effected from cultivating conditions and interaction of genotype $x$ environment. These properties generally defined as viscoelasticity and known as balance between expansion and viscoelasticity that effect last usage quality. For example dough that has high elasticity is used for bread making, dough has high expansion is used for making cakes and biscuits. Proteins that determine viscoelastic properties of dough and format of reticulated structure known as gluten protein. As a result gluten proteins are studied by a lot of researchers during 250 years because of their determination capability of wheat products produced from wheat flour.
\end{abstract}

Keywords: Wheat, Quality, Gluten, Protein

\section{Wheat Flour Contents}

Cereals grain protein content is about \%10-12 and this value is lower than legumes. Although legumes whose protein content is about $20-40 \%$, cereals used for human nutrition significantly. Cereals contribute to human nutrition with 200 million tones protein production. And this value equals $50 \%$ of world population protein need [1].

\subsection{Starch}

Shape and size of starch granules changes according to variety. These properties are associated with grinding, mechanical damage and grain hardness. Differences of protein concentration are more effective than starch granule size for bread making quality. On bread making technology starch is associated with bread rancidity [2][3][4].

\subsection{Lipid}

Lipids are effective components on bread making quality although having low levels. A part of lipids form some organic components called starch lipids who has non covalent bonds and this formation makes explanation on bread rancidity associated starch and lipid interaction [5][6].

\subsection{Protein}

Protein fractions are components that have marked effects on bread making [7]. Bread making quality is associated with specific proteins and unit and subunits of these proteins. Further; quality is affected by monomeric and polymeric protein presence and those proteins distribution significantly [1][8]. 


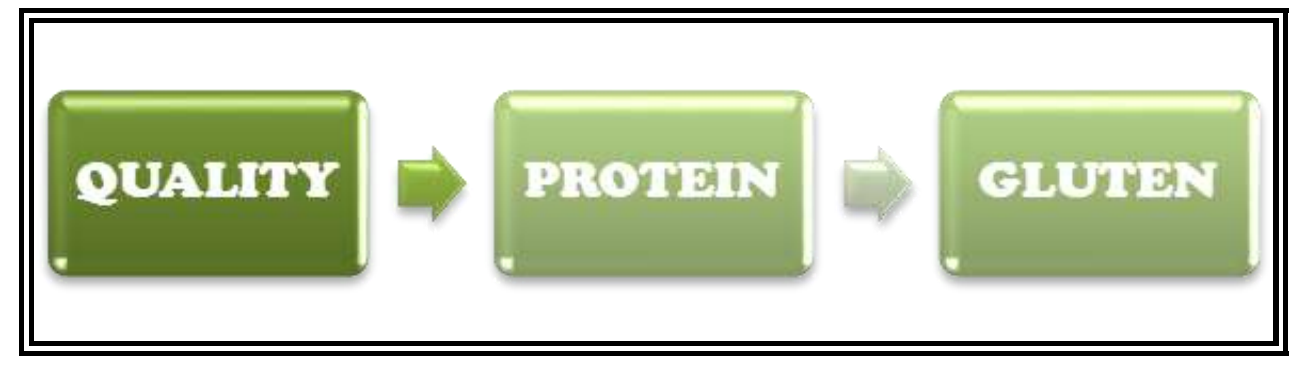

\section{Quality has different meanings;}

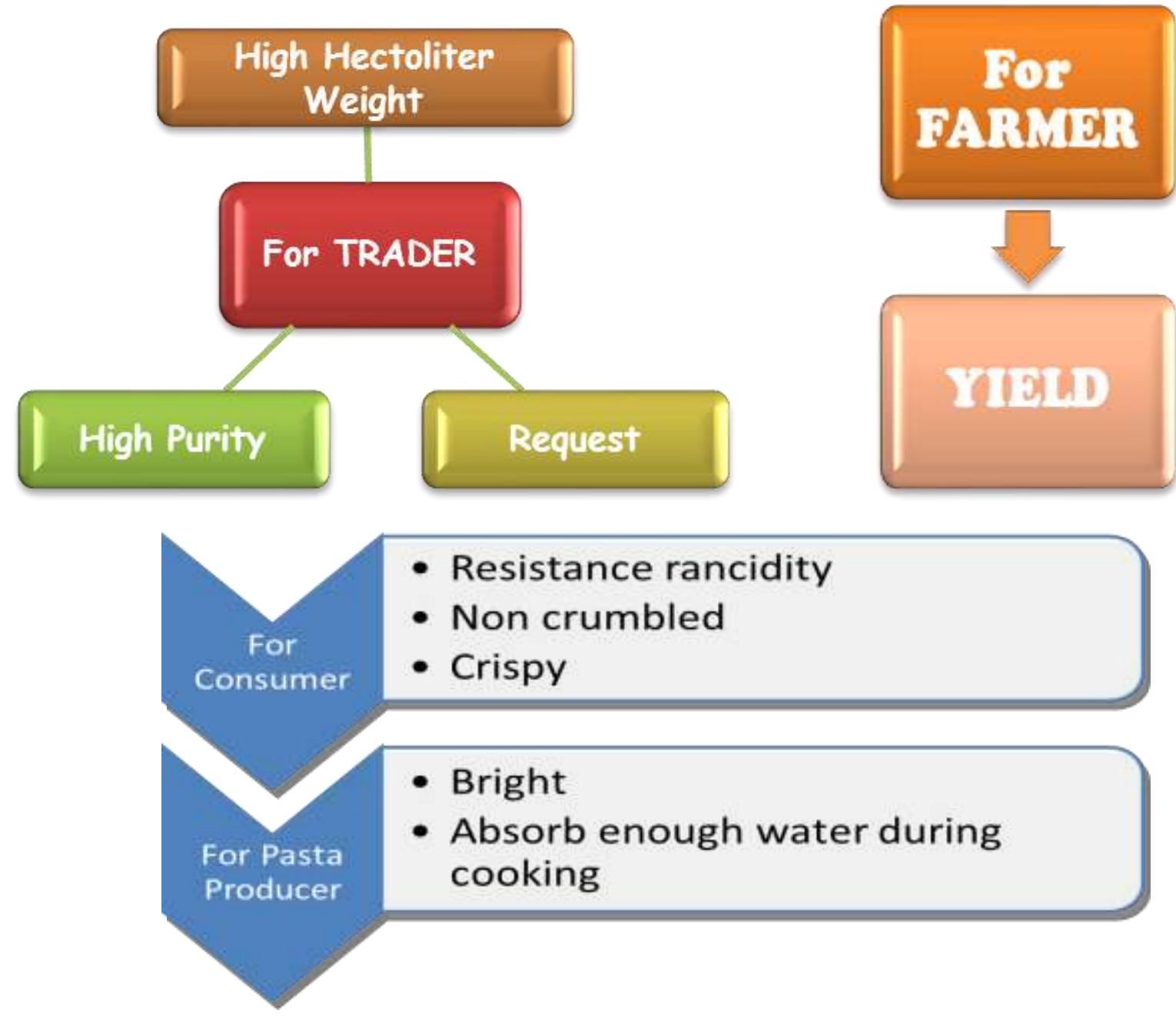

\section{Wheat Storage Proteins}

Processing of wheat flour to different products is depends on gluten that is a storage protein. Because of this, researches on gluten include 250 years duration. Beside of functional properties of gluten proteins their extraordinary structure and properties triggers studies at this area [1][9]. Gliadin and glutenin from storage proteins are basic components who determine cooking properties and build gluten polymers [10]. Wheat gluten proteins include major storage proteins at wheat developing grain starch endosperm. This form is format a matrix with proteins at dry ripe grain and a viscoelastic network became during mixing flour with water for dough making. This viscoelastic property is supports transformation of wheat to other products [11]. 


\subsection{Gluten}

A wide range of wheat that uses for human nutrition is wheat flour and produces with grinding and separation of embryo and bran. So starch endosperm that has high levels starch and gluten is very important. Gluten proteins form a matrix at dry and ripe endosperm cells. When wheat flour units with water and formatted dough, protein matrixes of each cell come together and formatted a permanent structure. This situation provides processing like fermentation of bread and transformation of dough to some other products like pasta [12].

Gluten proteins are linked each other with disulphide bonds that brings viscoelastic properties to dough and polymeric structures. Glutens are elastic structures obtained after washing dough with salty water. Gluten formats $75 \%$ of dry mass; other parts are lipids and starch. When glutens treated with reducing agents and analyses with electrophoresis sub units are separated according to their masses like HMW-GS(high molecular weight gluten subunits) and LMW-GS(low molecular weight gluten subunits)[13][14].

Each polypeptide synthesis ribosomes of endoplasmic reticulum with ribosomes and transferred lumen by losing $\mathrm{N}$ terminal signal peptide then format quaternary protein structure by formation of disulphide bonds in Lumen [11][15][16].

Wheat endosperm does not exist to provide flour for human nutrition. It's aim is provide nutrition to seed for germination. So biologic role of gluten protein is providing seed storage $\mathrm{C}, \mathrm{N}$, and $\mathrm{S}$ for germination and seedling. There is no other biologic role of gluten protein and its viscoelastic properties are role of genetically interactions [11][17].

Gluten protein doesn't dissolve with water and it has a permanent structure during bread making process. It hydrates with water and interact with other dough components easily through it's hydrophilic and hydrophobic parts and collects all dough components, so dough can format in a short time and can be developed easily. It formats complexes with lipids and use starch as filling component so a stronger structure formats. It brings a viscoelastic property to bread dough. It makes dough stronger by $\mathrm{S}-\mathrm{S}$ covalent bounds and by non-covalent bonds like (ion, hydrogen and Van der Waals). These properties make dough stronger and make it stabile during bread making processes like kneading, partition, rounding and fermentation. Gluten can keep air entered dough and $\mathrm{CO}_{2}$ gases produces by yeast by formatting a matrix with starch and with other surfactant components like glutenin and gliadin by it's strong network structure. So it provides making soft, porous, and fluffy and volume productions because of providing elastic and plastic properties to dough. When dough cooks, temperature increases, starch gelatinized, gluten coagulated and both components makes semi-rigid and less fragile structure and this is a basic component group that formats basic structure [1].

\subsection{Gliadin}

Much of gliadins are as monomers. Gliadins are classified according to their mobility at low $\mathrm{pH}$ electrophoresis as $\alpha, \beta, \gamma$ and $\omega$ gliadins [13][18]. Although $\alpha, \beta, \gamma$ and $\omega$ gliadins are generally similar to each other, $\omega$ gliadins include low level cysteine and methionine and include basic amino acids lower than others. All of gliadins are monomers that do not include disulphide bonds [1][19]. It is thought that during dough formation gliadins do not format covalent bonds inside big elastic networks like glutens. But it is known that gliadins bring important properties like reologic, elastic properties with viscosity and expansion to dough. Gliadins can interact with hydrogen bonds [1][20].

\subsection{Glutenin}

It is reported that glutenin is the base of functional wheat proteins derivatives; gliadins have only dilution function but attributes glutenin properties significantly [13][21]. Glutenin fractions are form polymer mixtures as HMW-GS and LMW-GS. Big glutenin polymers are stabilized by disulphide bonds [18][22].

\subsection{Albumins and Globulins}

Albumins dissolve water and globulins dissolve saline water that form big part of wheat proteins create $\%$ 10-22 of total flour protein. $\alpha$-amylase/trypsin inhibitors, serpins and purotionins have function on preventing insect and fungi damage beside of being nutrition reserve for germinating seed. Puroindolines are effective on grain hardness. Both amino acids are important for nutrition because of including essential amino acids [1][23]. 


\section{Important Factors Effect Quality}

\subsection{Temperature}

Accumulation of protein fractions of grain is spread different plant development stages. High temperature or drought that is shortened grain filling period effects protein fractions balance. Although water deficit effects on last production quality of much wheat varieties, there is limited knowledge about water deficit and protein fraction interaction. When gliadins and high and low molecular weight glutenin subunits accumulation kinetic is investigated at normal conditions, it is detected that drought has no important effect on protein fraction accumulation activities. Similarly drought that is encountered during before pollination didn't effect accumulation rate of SDS soluble and non-soluble polymers but shortened grain filling period [24][25].

\subsection{Nitrogen}

It is reported that $\mathrm{N}$ application is the most important environmental factor that affects protein content by a lot of researchers. Most important quantitative effect of $\mathrm{N}$ is, increasing total protein, protein accumulation and subunit contents of grain by nitrogen application. By increasing grain protein rate gliadin and glutenin content and rate of gliadins and glutenin will increase also. Gliadins show higher correlation with total protein level than glutenin. Amino acid composition changes according to gliadin, glutenin rate and nitrogen content and this rate is increases according to $\mathrm{N}$ concentration of grain. It is detected that some gliadin bands concentration measured by electrophoresis and densitometer is changed according to $\mathrm{N}$ level [24][26].

\subsection{Sulfur}

Effects of sulfur to dough properties is related with it's benefits to prolamin composition. Quantitative distribution of gluten proteins is effect sulfur fertilization significantly. As a result of sulfur deficit dough resistance and rate of HMW-GS to LMW-GS is increased. Decreasing of dough expansion is related with decreasing of LMW-GS and a, b and g types gliainds [24].

\subsection{Suni Bug Damage}

Suni bug damage that is performed by insects called Eurygaster and Aelia that live Middle East Europe and some parts of Mediterranean. Beside of them some other insects like Nysius huttoni (Zeland), Chlorocha sayi (Sthal) and Stodiplosis mosellana Gehin (South America) have negative effects on wheat productions cooking quality. Suni bug is (Eurogaster spp. and Aelia spp.) decreases yield and quality in Turkey for long years. Damaged grains are wrinkled compared with healthy grains. Hectoliter weight, spike weight and spike height is lower of damaged grains than healthy samples but protein rate is not different. Grain condition has directly effects on flour yield and quality. Flour yield of bug damaged grains is decreased by increasing of damaged spike number.

This situation is valid in hectoliter weight, spike height and spike length. Bug damage effects protein quality more than protein content. Those kinds of grains farinographic properties are changed significantly beside water absorption [24]. Dough quality criteria and some alveogram values decrease about $3 \%$ at damaged grains.

Flour that was damaged by Heteropteran before harvesting is not suitable for bread making. Those insects (Eurygaster spp., Aelia spp., and Nysius huttoni) attack developing wheat spikes and inject some kind of enzymes for making grain nutrition soluble. Those secretory agents include protease that disrupts gluten structure during mixing and fermentation. This situation decreases gluten resistance and cause decline reologic properties so bread characteristics change negatively [1].

\section{References}

[1] R. Kuktaite, "Protein quality in wheat: changes in protein polymer composition during grain development and dough processing",pHD Thesis, Dep. of Crop Science Alnarp, Swedish University, Sweden, 2004.

[2] J. Lelievre, K. Lorenz, P. Meredith, D. W. Barush, "Effects of starch particle size and protein concentration on bread making performance", Starch/Stärke, vol.39, pp.347-352, 1987.

http://dx.doi.org/10.1002/star.19870391004

[3] E. J. Bass, "Wheat flour milling" In Wheat chemistry and technology, pp. 1-68 1988. 
[4] R. C. Hoseney, K. F. Finney, M. D. Shogren, Y. Pomeranz, "Functional (breadmaking) and biochemical properties of wheat flour components", VIII. Starch. Cereal Chemistry, vol.48, pp.191-201, 1971.

[5] W. R. Morrison, "Lipids", In Wheat: chemistry and technology, pp.373-439, 1988.

[6] F. MacRitchie, "Baking quality of wheat flours", Advances in Food Nutrition Research, vol.29, pp.201-277, 1984. http://dx.doi.org/10.1016/s0065-2628(08)60058-0

[7] J. S. Wall, "The role of wheat proteins in determining baking quality", In Recent advances in the biochemistry of cereals, pp.275-311, 1979.

[8] R. B. Gupta, K. Khan, F. MacRitchie, "Biochemical basis of flour properties in bread wheats", Journal of Cereal Science, vol.18, pp.23-41, 1993.

http://dx.doi.org/10.1006/jcrs.1993.1031

[9] P. L. Weegels, A. M. Pijpekamp, A. Graveland, R. J. Hamer, J. D. Schofield, "Depolymerisation and repolymerisation of wheat glutenin during dough processing", Journal of Cereal Science, vol.23, pp.103-111, 1996. http://dx.doi.org/10.1006/jcrs.1996.0010

[10] P. S. Belton, A. M.Gil, A. Grant, E. Alberti, A. S. Tatham, "Proton and carbon NMR measurements of the effects of hydration on the wheat protein omega gliadin" Spectrochimica Acta A, vol.54, pp.955-966., 1998.

http://dx.doi.org/10.1016/S1386-1425(98)00025-0

[11] P. R. Shewry, N. G. Halford, "Cereal seed storage proteins: structures, proterties and role in grain utilization", Journal of Experimantal Botany, vol.53, pp.947-958, 2002. http://dx.doi.org/10.1093/jexbot/53.370.947

[12] P. R. Shewry, N. G. Halford, P. S. Belton, A. S. Tahtam, "The structure and properties of gluten: an elastic protein from wheat grain", Phil. Trans. R. Soc. Lond, vol.357, pp.133-142, 2002.

http://dx.doi.org/10.1098/rstb.2001.1024

[13] A. Torbica, M. Antov, J. Mastilovic, D. Knezevic, "The influence of changes in gluten complex structure on technological quality of wheat (Triticum aestivum L.)", Food Research International, vol.40, pp.1038-1045, 2007. http://dx.doi.org/10.1016/j.foodres.2007.05.009

[14] Y. G. Wang, K. Khan, G. Hareland, G. Nygard, “Quantitative glutenin composition from gel electrophoresis of flour mill streams and relationship to breadmaking quality”, Cereal Chemistry, vol.83, pp.293-299, 2006.

http://dx.doi.org/10.1094/CC-83-0293

[15] P. R. Shewry, A. S. Tatham, N. G. Halford, "The prolamins of the Triticeae" pp. 33-78.

[16] P. R. Shewry, A. S. Tatham, J. Forde, M. Kreis, B. J. Miflin, "The classification and nomenclature of wheat Gluten proteins: a reassessment", J. Cereal Sci., vol. 4, pp.97-106, 1986. http://dx.doi.org/10.1016/S0733-5210(86)80012-1

[17] D. K. Mecham, C. Knapp, “The sulphydryl contents of doughs mixing under nitrogen”, Cereal Chem., vol. 43, pp. 226, 1966.

[18] Wieser, H., "Chemistry of Gluten proteins" Food Microbiology, vol.2, pp.115-120, 2007. http://dx.doi.org/10.1016/j.fm.2006.07.004

[19] S. Müller, H. Wieser, "Disulphide bonds of alfa-type gliadins”, Journal of Cereal Science, vol. 22, pp.21-27, 1995. http://dx.doi.org/10.1016/S0733-5210(05)80004-9

[20] P. S. Belton, "On the elasticity of wheat gluten”, Journal of Cereal Science, vol.29, pp.103-107, 1999. http://dx.doi.org/10.1006/jcrs.1998.0227

[21] J. Xu, J. A. Bietz, C. J. Carriere, "Viscoelastic properties of wheat gliadin and glutenin suspensions", Food Chemistry, vol.101(3), pp.1025-1030, 2007. http://dx.doi.org/10.1016/j.foodchem.2006.02.057

[22] H. Wieser, R. Kieffer, "Correlations of the amount of gluten protein types to the technological properties of wheat flours determined on a micro-scale", J. Cereal Sci., vol. 34, pp.19-27, 2001.

http://dx.doi.org/10.1006/jcrs.2000.0385

[23] J. D. Schofield, M. R. Booth, "Wheat proteins and their technological significance" London, Applied Science Publishers), 1-65 pp, 1983.

[24] A. Torbica, M. Antov, J. Mastilovic, D. Knezevic, "The influence of changes in gluten complex structure on technological quality of wheat (Triticum aestivum L.)", Food Research International, vol.40, pp.1038-1045, 2007. 
http://dx.doi.org/10.1016/j.foodres.2007.05.009

[25] E. Triboï, A. Abad, A. Michelena, J. Lloveras, J. L. Ollier, C. Daniel, "Environmental effects on the quality of wheat genotypes", Eur. J. Agron., vol.13, pp.47-64, 2000.

http://dx.doi.org/10.1016/S1161-0301(00)00059-9

[26] C. Daniel, E. Triboï, "Effects of temperature and nitrogen nutrition on the grain composition of winter wheat: effects on gliadin content and composition", J. Cereal Sci., vol.32, pp.45-56, 2000.

http://dx.doi.org/10.1006/jcrs.2000.0313 